\title{
Identifying the Stroke Mimics
}

This article was published in the following Dove Press journal:

International Journal of General Medicine

\author{
Ajay Kumar Mishra' \\ Harshad Arvind Vanjare (iD) ${ }^{2}$ \\ Anu Anna George' \\ Kamal Kant Sahu (iD) \\ 'Department of Internal Medicine, Saint \\ Vincent Hospital, Worcester, MA, USA; \\ ${ }^{2}$ Department of Radiology, Christian \\ Medical College, Vellore, India
}

\begin{abstract}
Individuals presenting with sudden and focal neurological findings are usually suspected to have stroke. However, there are other conditions that can simulate stroke, which are often referred to as stroke mimics. Awareness and understanding these stroke-like disorders are of extreme importance as the treatment of each of them might be variable. We hereby briefly discuss these stroke mimics, common differentials, and key features to differentiate amongst the various causes of acute neurological event. Stroke is one of the neurological emergencies that needs urgent intervention to prevent significant mortality and morbidity. At the same time, it is important to realize the importance of other conditions which may mimic to stroke. In this letter, we aim to discuss a few key features that could probably help to distinguish stroke from mimickers thereby helping emergency doctors, neurologists, and hospitalists in streamlining the correct treatment at the earliest.
\end{abstract}

Keywords: COVID-19, stroke, virus, SARS-CoV-2, neurology

\section{Prevalence of Stroke Mimics (Community vs Health Care Settings)}

Stroke mimics accounts for approximately $25 \%$ of probable stroke admissions. Marot et al have reported 368 clinical episodes of presumed stroke, among which $50 \%$ were actual vascular episodes. ${ }^{1}$ In another retrospective study published in 2019, Garg et al reported $27.3 \%$ of stroke mimics. ${ }^{2}$ Interestingly, in another prospective study, Matuja et al recruited 1403 patients; among those, $30.6 \%$ were presumed to have a stroke. Only $6.6 \%$ of these were identified to have stroke mimics. ${ }^{3}$

Hospital-based studies could have higher reported numbers of stroke mimics as compared to community-based study probably due to

1. Selection bias of having sicker patients with more vascular risk factors. ${ }^{4}$

2. Observation and reporting bias in having higher reporting of stroke-like episodes, including change in cognition, dropping of the eyelid, and limb weakness while being closely monitored. ${ }^{1,5,6}$

Meanwhile, community-based studies would report a lesser number of stroke episodes because of possible loss of continuous recruitment of patients and decreased health-seeking behavior. While the actual rates of stroke mimics continue to be diverse, it is irrefutable that stroke mimics continue to be a significant challenge to the treating clinician. ${ }^{7,8}$
Correspondence: Kamal Kant Sahu Department of Internal Medicine, Saint Vincent Hospital, Worcester, MA 01608, USA

Email drkksahu85@gmail.com 


\section{Calling a Stroke "Stroke"}

Computed tomography of the brain is routinely used in the assessment of stroke, as it facilitates the decision regarding the administration of thrombolytic agents. In the Marot et al's study, only 2 of the stroke mimics received IV rt-PA. ${ }^{1}$ In the study by Garg et al, all 33 patients with stroke mimics received rt-PA as per the treatment protocol. ${ }^{2}$ With the significant mortality benefit offered by rt-PA, the harm of not administering the same to a patient is higher. However, the modality of imaging could influence the unnecessary administration of thrombolytic agent to patients at low risk in terms of clinical presentation and vascular risk profile. Magnetic Resonance Imaging (MRI) can not only show diffusion restriction but also identify granulomas, dilated Virchow robin spaces, cysts better, and differentiate them from a vascular event. Image 1 shows the MRI brain's findings of a 20-year-old female with headache and acute onset of aphasia who had an initial non-diagnostic CT but later diagnosed to be angioinvasive aspergillosis with the contributory clue from MRI (Figure 1). In a recent study by Matujia et al, improved rate of detection of mimics was secondary to better identification and differentiation of vascular events by MRI. In the absence of MRI, we agree that a detailed clinical history and examination would significantly influence the diagnosis of stroke in lowrisk patients.

In high-risk patients, the role of administration of rt-PA in stroke mimics has been studied as well. Ahmed et al studied 72,582 patients from 485 US hospitals with suspected ischemic stroke who received

alteplase. ${ }^{9}$ Among all the recruited patients, only 3.5\% of stroke mimics received alteplase. Intracranial hemorrhage and in-hospital mortality were $0.4 \%$, and $0.8 \%$ in the mimics compared to $3.5 \%$ and $6.2 \%$ of patients with ischemic stroke. ${ }^{9,10}$

\section{Identifying the Stroke Mimics and the Uncommon Causes of Stroke}

In Marot et al's study, $48.4 \%$ of stroke mimics did not get a definitive clinical diagnosis. This pattern was reported in the study by Ahmed et al as well. ${ }^{9}$ A total of $61.3 \%$ of stroke mimics in their study had an uncertain diagnosis and missing details. Gomez et al included 4570 presumed stroke cases, among which 404 were diagnosed with stroke mimics. They used a broader differential diagnosis and identified an etiology in around $90 \%$ of patients. ${ }^{11}$ Across studies identifying all the causes of stroke, mimics continue to be a challenge. ${ }^{6}$ Table 1 shows the multiple stroke mimics that have been reported in the literature. ${ }^{12-14,15,16}$ Future studies should incorporate broader differential and detailed workup.

In conclusion, stroke mimics are reported all over the world. They continue to be a diagnostic challenge to the treating emergency physician, neurologist, and clinician. A detailed history, neurological examination, appropriate neuroimaging, laboratory findings, and a multidisciplinary approach would facilitate understanding of these mimics and optimal care of these patients.

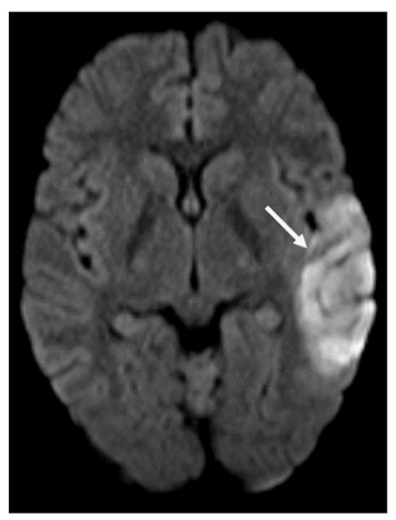

C

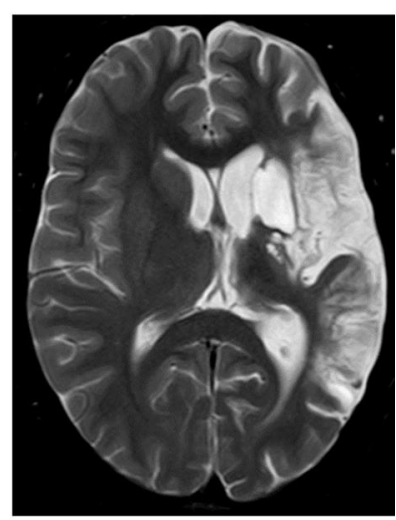

D

Figure I Angioinvasive aspergillosis in a 20-year-old female with headache and acute onset aphasia. (A) T2W axial section shows inflammatory changes in the sphenoid sinus (white arrow) with altered signal intensity in the adjacent medial aspect of the left temporal lobe (black arrow). (B) Post contrast TIW axial section shows enhancing area in the region of left temporal lobe signal abnormality. (C) Diffusion study shows an acute infarct in the left temporal lobe related to infective vasculitis of left middle cerebral artery (white arrow). (D) Follow up T2W axial section after 15 months shows chronic infarcts in the left MCA territory. 
Table I Various Stroke Mimics Described in the Literature

\begin{tabular}{|c|c|}
\hline Category & Etiology \\
\hline Central Nervous System & $\begin{array}{l}\text { I. Seizure } \\
\text { 2. Migraine: Typical and Hemiplegic } \\
\text { 3. Multiple sclerosis } \\
\text { 4. Brain tumors } \\
\text { 5. Subdural hemorrhage } \\
\text { 6. Parkinsonism } \\
\text { 7. Amyotrophic Lateral sclerosis } \\
\text { 8. Cognitive decline } \\
\text { 9. Meningeal carcinomatosis }\end{array}$ \\
\hline Peripheral Nervous system & $\begin{array}{l}\text { I. Peripheral vertigo } \\
\text { 2. Cranial neuropathies } \\
\text { 3. Diabetic neuropathy }\end{array}$ \\
\hline $\begin{array}{l}\text { Infections and immune } \\
\text { mediated }\end{array}$ & $\begin{array}{l}\text { I. Encephalitis } \\
\text { 2. Brain abscess } \\
\text { 3. Sepsis } \\
\text { 4. Limbic encephalitis } \\
\text { 5. Neurosarcoidosis }\end{array}$ \\
\hline Vascular & $\begin{array}{l}\text { I. Hypertensive encephalopathy } \\
\text { 2. PRES } \\
\text { 3. RCVS } \\
\text { 4. Hypotension } \\
\text { 5. Internal carotid artery } \\
\text { hypoperfusion } \\
\text { 6. Venous infarcts }\end{array}$ \\
\hline Metabolic & $\begin{array}{l}\text { I. Hyponatremia } \\
\text { 2. Hypo/Hyperglycemia } \\
\text { 3. Hyperammonemia } \\
\text { 4. Uremic encephalopathy } \\
\text { 5. Hepatic encephalopathy }\end{array}$ \\
\hline Psychiatric & $\begin{array}{l}\text { I. Anxiety } \\
\text { 2. Conversion disorder } \\
\text { 3. Transient global amnesia } \\
\text { 4. Post Electroconvulsive therapy }\end{array}$ \\
\hline Others & $\begin{array}{l}\text { I. Alcohol related } \\
\text { 2. Syncope } \\
\text { 3. Osteomuscular } \\
\text { 4. Drugs } \\
\text { 5. Toxins }\end{array}$ \\
\hline
\end{tabular}

\section{Disclosure}

The authors report no conflicts of interest in this work.

\section{References}

1. Marot JE, Rebeiz T, Kramer C, et al. Neurological examination, rather than vascular risk factor assessment, serves to distinguish strokes from stroke mimics [published online ahead of print, 2020 Jul 17]. World Neurosurg. 2020:S1878-8750(20)31596-5. doi:10.1016/j.wneu.2020. 07.075
2. Garg R, Rech MA, Schneck M. Stroke mimics: an important source of bias in acute ischemic stroke research. J Stroke Cerebrovasc Dis. 2019;28(9):2475-2480. doi:10.1016/j.jstrokecerebrovasdis.2019.0 6.019

3. Matuja SS, Khanbhai K, Mahawish KM, Munseri P. Stroke mimics in patients clinically diagnosed with stroke at a tertiary teaching hospital in Tanzania: a prospective cohort study. BMC Neurol. 2020;20(1):270. doi:10.1186/s12883-020-018 $53-7$

4. Sahu KK, Mishra AK, Lal A, Kranis M. An interesting case of expressive aphasia: enterococcus faecalis-related infective endocarditis complicating as septic emboli. QJM. 2020;113(2):146-147. doi:10.1093/qjmed/hcz169

5. Vanjare HA, Mannam P, Mishra AK, et al. Brain imaging in cases with positive serology for dengue with neurologic symptoms: a clinicoradiologic correlation. AJNR Am J Neuroradiol. 2018;39 (4):699-703. doi:10.3174/ajnr.A5544

6. Mishra A, Binu A, Abraham G, Vanjare H, George T, Iyadurai R. Cerebrovascular injury following scorpion sting and snake envenomation: a case series. Can J Neurol Sci. 2018;45(6):669-674. doi:10.1017/cjn.2018.328

7. Thomas VV, George T, Mishra AK, Mannam P, Ramya I. Lateral medullary syndrome after a scorpion sting. $J$ Family Med Prim Care. 2017;6(1):155-157. doi:10.4103/2249-4863.214 988

8. Mishra AK, Sahu KK, George AA, Sargent J, Lal A. Cerebrovascular events in COVID-19 patients. Monaldi Arch Chest Dis. 2020;90(2). doi:10.4081/monaldi.2020.1341

9. Ali-Ahmed F, Federspiel JJ, Liang L, et al. Intravenous tissue plasminogen activator in stroke mimics. Circ Cardiovasc Qual Outcomes. 2019;12(8):e005609. doi:10.1161/CIRCOUTCOMES. 119.005609

10. Mishra AK, Iyadurai R. Prehospital and hospital delays for stroke patients treated with thrombolysis: access to health care facility still a bottle neck in stroke care in developing nation. Australas Emerg Care. 2019;22(4):227-228. doi:10.1016/j.auec.2019.07. 003

11. Avellaneda-Gómez C, Rodríguez Campello A, Giralt Steinhauer E, et al. Estudio descriptivo de los stroke mimics después de un estudio neurovascular completo [Description of stroke mimics after complete neurovascular assessment]. Neurologia. 2019;34(1):7-13. doi:10.1016/j.nrl.2016.10. 006

12. Mishra AK, Vanjare HA, Raj PM. Cryptococcal meningitis presenting as acute onset bilateral cerebellar infarct. J Neurosci Rural Pract. 2017;8(1):159-160. doi:10.4103/0976-3147.193 537

13. Mishra AK, Aaron S, Abhilash K, et al. Simple telephone call a feasible, useful and acceptable method of following up patients with cerebrovascular accidents: prospective Cohort study in South India. Int $J$ Stroke. 2016;11(8):NP87-NP88. doi:10.1177/ 1747493016654486

14. Ifergan $\mathrm{H}$, Amelot $\mathrm{A}$, Ismail $\mathrm{M}$, Gaudron $\mathrm{M}$, Cottier J-P, Narata AP. stroke-mimics in stroke-units. evaluation after changes imposed by randomized trials. Arq Neuropsiquiatr. 2020;78(2):88-95. doi:10.1590/0004-282x20190154

15. Meng D, AlSaeed M, Randhawa J, Chen T. Retrosplenial stroke mimicking transient global amnesia. Can $J$ Neurol Sci. 2021;12:1-7. doi:10.1590/0004-282x20190154

16. Lim EYT, Swaminathan SK. Cerebral contrast staining mimicking parenchymal haemorrhage in a stroke patient. BMJ Case Rep. 2020;13(12):e236400. 


\section{Publish your work in this journal}

The International Journal of General Medicine is an international, peer-reviewed open-access journal that focuses on general and internal medicine, pathogenesis, epidemiology, diagnosis, monitoring and treatment protocols. The journal is characterized by the rapid reporting of reviews, original research and clinical studies across all disease areas. The manuscript management system is completely online and includes a very quick and fair peer-review system, which is all easy to use. Visit http://www.dovepress.com/ testimonials.php to read real quotes from published authors. 